\title{
Compact Notch Filter Design Using Stepped Impedance Resonators for Sharp Roll-Off and Large Wideband Rejection
}

\author{
H. Asadbeigi, ${ }^{1}$ B. S. Virdee ${ }^{2}$ \\ ${ }^{1}$ Department of Electronics, Toyserkan Branch, Islamic Azad University, Toyserkan, Iran \\ ${ }^{2}$ Faculty of Life Sciences and Computing, Centre for Communications Technology, London \\ Metropolitan University, London, United Kingdom
}

Received 28 July 2014; accepted 13 November 2014

\begin{abstract}
This article presents the design of a compact notch filter with a sharp roll-off and high rejection over a wideband. The filter comprises stepped impedance resonators that are interconnected to each other at strategic points on the resonator for optimal $3 \mathrm{~dB}$ rolloff and high rejection over a wide stop-band. The fabricated third-order filter exhibits a steep $3 \mathrm{~dB}$ roll-off and rejection exceeding $50 \mathrm{~dB}$ over the frequency range 2.706.19 GHz. (c) 2014 Wiley Periodicals, Inc. Int J RF and Microwave CAE 25:490-494, 2015.
\end{abstract}

Keywords: wideband notch filter; microstrip filter; sharp roll-off filter

\section{INTRODUCTION}

Notch or bandstop filters (BSFs) are widely used in modern communication systems to eliminate unwanted signals, harmonics, and interference. Several methods have been previously reported to design and implement BSFs. In [1], the authors present a BSF design using periodic pairs of L-shaped strips that are embedded inside a ground-plane slot, and insert periodic pairs of L-shaped stubs in the microstrip transmission-line. Reported in [2] is a comparative study on designing BSF using split-ring resonator and complementary split-ring resonator. In [3], it is shown that by defecting the ground-plane with two semicomplementary split-ring resonators and etching two line resonators within the input/output microstrip-line results in a structure that exhibits bandstop function. The above examples use defected ground structure (DGS) technology that has several shortcomings, namely: (1) high fabrication cost; (2) low immunity to crosstalk; (3) ground-plane interference; and (4) relatively large size. Other techniques of designing BSFs include using signal interference [4], where bandstop function is achieved by interfering signals propagating along two parallel transmission-lines

Correspondence to: H. Asadbeigi; e-mail: hamid.asadbeigi@ yahoo.com.

DOI: $10.1002 /$ mmce. 20883

Published online 9 December 2014 in Wiley Online Library (wileyonlinelibrary.com). having different electrical lengths and characteristic impedances. Although the filter provides a wideband response, however, its $3 \mathrm{~dB}$ roll-off and stop-band rejection is mediocre, and its size is large for practical applications. In [5], the authors use interdigital capacitor loaded loop resonators coupled to a meandering microstrip line to realize a BSF, however, its fractional bandwidth is low and its stop-band rejection poor.

In this article, a novel BSF structure is proposed that overcomes the shortcomings of the aforementioned techniques. A third-order BSF structure is fabricated to demonstrate that it exhibits the following characteristics: wide stop-band performance, steep $3 \mathrm{~dB}$ roll-off, high rejection level in the stop-band, low fabrication cost, and compact size.

\section{FILTER STRUCTURE AND DESIGN}

Microstrip stepped impedance resonator (SIR) consists of a high impedance section of characteristic impedance $Z_{1}$ and electrical length $\theta_{1}$ attached to two low impedance sections of characteristic impedances $Z_{2}$ and electrical length $\theta_{2}$, as shown in Figure 1 . The SIR is made more compact in size by folding inward the low impedance sections as shown in Figure 2a. The $L C$ equivalent model representing the resonator is depicted in Figure $2 b$, where $L_{\mathrm{t} 1}$ is the inductance of the tapped feed-line, $C_{\mathrm{t} 1}$ is the associated capacitance at the tapped feed-line, and $L_{\mathrm{t} 2}$ is the half inductance of the high impedance line connecting

(C) 2014 Wiley Periodicals, Inc. 


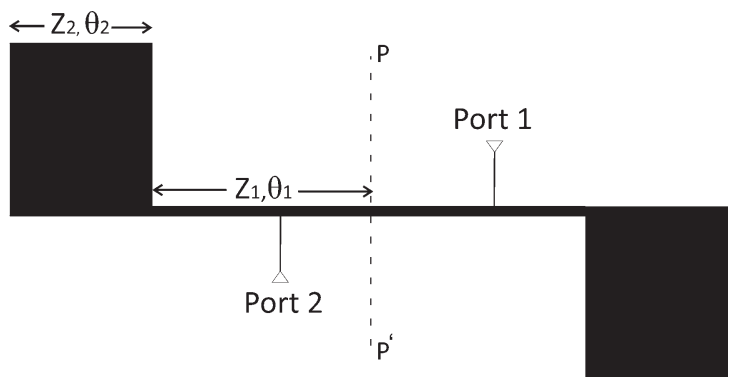

Figure 1 Structure of microstrip stepped impedance resonator.

the two feed-lines. The inductance $L_{\mathrm{t} 3}$ corresponds to the high impedance line. The elements $L_{\mathrm{t} 4}, C_{\mathrm{t} 2}$, and $L_{\mathrm{t} 5}$ in the dotted box represent the step impedance discontinuity, and $C_{\mathrm{t} 3}$ represents the low impedance section of the resonator. In the analysis, the SIR filter is considered to be symmetrical along the $P-P^{\prime}$ plane. The even-mode and odd-mode input impedance of $L C$ circuit can be then be determined. The odd-mode equivalent circuit of the SIR is represented in Figure 2c, where the input impedance $Z_{\text {ino }}$ is given by

$$
\begin{aligned}
& Z_{\text {ino }}=j \omega L_{\mathrm{t} 1}+\frac{1}{Y_{\text {ino }}^{\prime}} \\
& Y_{\text {ino }}^{\prime}=j \omega C_{\mathrm{t} 1}+\frac{1}{j \omega L_{\mathrm{t} 2}}+\frac{1}{Z_{\text {ino }}^{\prime \prime}} \\
& Z_{\text {ino }}^{\prime \prime}=j \omega\left(L_{\mathrm{t} 3}+L_{\mathrm{t} 4}\right)+\frac{1}{{ }^{\prime \prime \prime} Y_{\text {ino }}}
\end{aligned}
$$

$$
{ }^{\prime \prime \prime} Y_{\mathrm{ino}}=j \omega C_{\mathrm{t} 2}+\frac{j \omega C_{\mathrm{t} 3}}{1-\omega^{2} L_{\mathrm{t} 5} C_{\mathrm{t} 3}}
$$

The even-mode input impedance $Z_{\text {ine }}$ in Figure $2 d$ can be determined using

$$
\begin{gathered}
Z_{\text {ine }}=j \omega L_{\mathrm{t} 1}+\frac{1}{Y_{\text {ine }}^{\prime}} \\
Y_{\text {ine }}^{\prime}=j \omega C_{\mathrm{t} 1}+\frac{1}{Z_{\text {ine }}^{\prime \prime}} \\
{ }^{\prime \prime} Z_{\text {ine }}=j \omega\left(L_{\mathrm{t} 3}+L_{\mathrm{t} 4}\right)+\frac{1}{{ }^{\prime \prime \prime} Y_{\text {ine }}} \\
{ }^{\prime \prime} Y_{\text {ine }}=j \omega C_{\mathrm{t} 2}+\frac{j \omega C_{\mathrm{t} 3}}{1-\omega^{2} L_{\mathrm{t} 5} C_{\mathrm{t} 3}}
\end{gathered}
$$

The $S_{21}$ and $S_{11}$ parameters can be derived using [6]:

$$
\begin{gathered}
S_{21}=\frac{Z_{\mathrm{o}}\left(Z_{\text {ine }}-Z_{\text {ino }}\right)}{\left(Z_{\mathrm{o}}-Z_{\text {ine }}\right)\left(Z_{\mathrm{o}}+Z_{\text {ino }}\right)} \\
S_{11}=\frac{Z_{\mathrm{o}}\left(Z_{\text {ine }} Z_{\text {ino }}-1\right)}{\left(Z_{\mathrm{o}}+Z_{\text {ine }}\right)\left(Z_{\mathrm{o}}+Z_{\text {ino }}\right)}
\end{gathered}
$$

The dimensions of filter layout in Figure 2a are: $L_{1}=3.8 \mathrm{~mm}, L_{2}=1.25 \mathrm{~mm}, L_{3}=0.87 \mathrm{~mm}, L_{4}=3 \mathrm{~mm}$, $W_{1}=0.2 \mathrm{~mm}, W_{2}=6 \mathrm{~mm}$, and $W_{f}=1.3 \mathrm{~mm}$. The simulated $S$-parameters as a function of $L_{1}$ are shown in Figure 3a. By decreasing $L_{1}$ from 3.8 to $2.8 \mathrm{~mm}$ in steps of $0.5 \mathrm{~mm}$, the two transmission zeros move towards the low

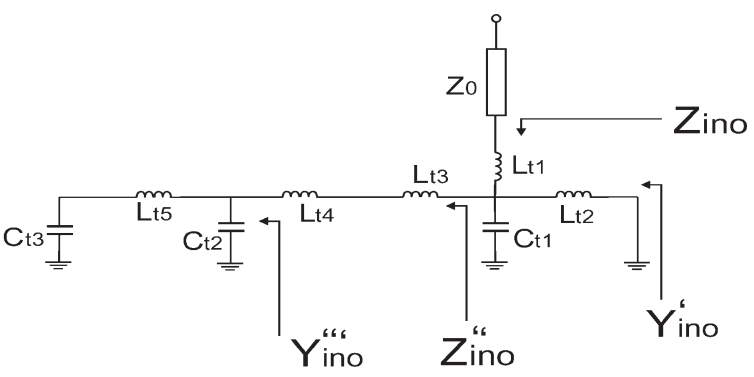

(c)

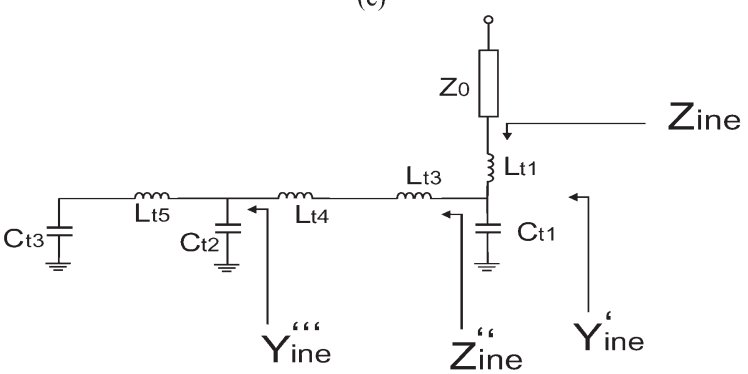

(d)

Figure 2 Layout of the single order filter and its equivalent odd- and even-mode circuits. (a) Layout of single order BSF, (b) $L C$ equivalent circuit model of the single order BSF, (c) odd-mode equivalent model, and (d) even-mode equivalent model. 


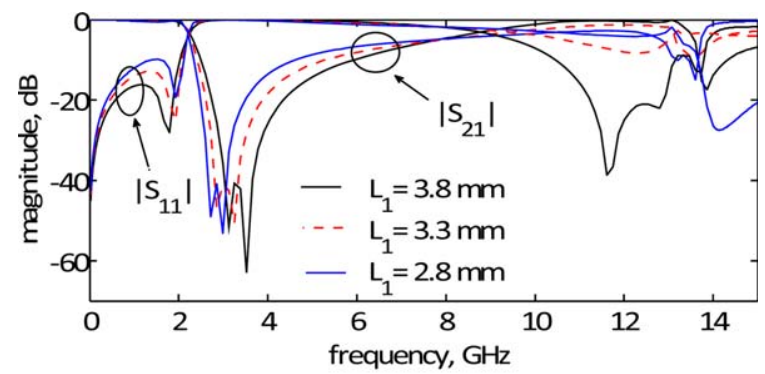

(a)

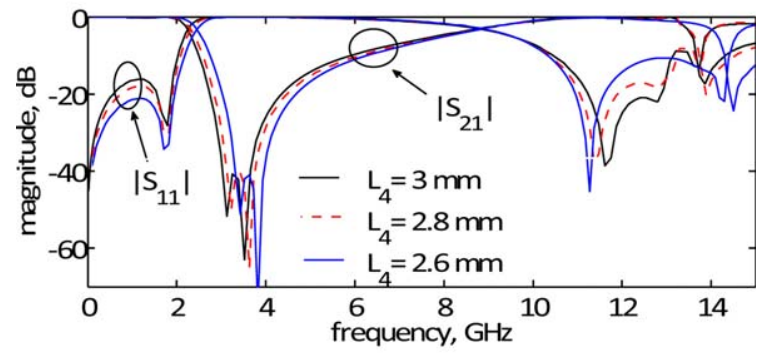

(b)

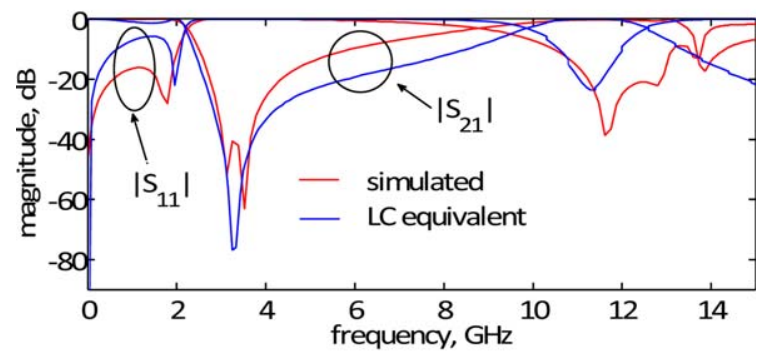

(c)

Figure 3 Simulated transmission and reflection-coefficient responses for microstrip layout dimensions $L_{1}$ and $L_{4}$. (a) Simulated $S_{21}$ and $S_{11}$ response as a function of dimension $L_{1}$, (b) simulated $S_{21}$ and $S_{11}$ response as a function of dimension $L_{4}$, (c) simulated $S_{21}$ and $S_{11}$ response for single order BSF and the calculated response of the $L C$ equivalent circuit model.

frequency end, thus enabling the control of the filter skirt. Figure 3 b shows the $S$-parameters response when the magnitude of $L_{4}$ is varied from 3 to $2.6 \mathrm{~mm}$ in steps of $0.2 \mathrm{~mm}$. This graph shows that the $3 \mathrm{~dB}$ cut-off frequency is controlled by parameter $L_{4}$. The simulated $S$-parameters of the single order BSF and its equivalent circuit in Figures $2 \mathrm{a}$ and $2 \mathrm{~b}$, respectively, are presented in Figure 3c. There is good agreement between the two $S_{21}$ responses. The values of the $L C$ equivalent circuit model are: $L_{\mathrm{t} 1}=1.23 \mathrm{nH}, L_{\mathrm{t} 2}=1.52 \mathrm{nH}, L_{\mathrm{t} 3}=0.91 \mathrm{nH}, L_{\mathrm{t} 4}=0.08$ $\mathrm{nH}, L_{\mathrm{t} 5}=0.03 \mathrm{nH}, C_{\mathrm{t} 1}=402 \mathrm{fF}, C_{t 2}=295 \mathrm{fF}, C_{\mathrm{t} 3}=2.02$ $\mathrm{pF}$.

\section{HIGH-ORDER BSF DESIGN}

To achieve a highly sharp $3 \mathrm{~dB}$ cut-off frequency and significantly improved stop-band characteristics multiple SIRs where used that are interconnected using microstrip lines of dimensions $0.1 \times 0.1 \mathrm{~mm}^{2}$, as shown in Figure 4a. This configuration generates multiple transmission zeros that contribute toward enhancing the filter response. Figures $4 \mathrm{a}$ and $4 \mathrm{~b}$ show the structure of thirdorder filter and its corresponding frequency response, respectively. It can be observed that the skirt, the rejection level, and stop-band of the filter are significantly improved than the single order filter in Figure 2a. The effect on the $S_{21}$ frequency response by the various orders of filter is shown in Figure 4c. The results show the sharpness and stop-band rejection performance of the filter can be improved by increasing of the order of the filter. The seven order filter provides the optimum response in terms of sharp cut-off, rejection level, and stop-band performance.

The $L C$ equivalent circuit of the third-order filter is depicted in Figure 5a. As the microstrip section interconnecting the resonators is very short, the associated capacitance and the inductance are negligible and have been ignored in the circuit analysis. The frequency response of the third-order filter, in Figure 5b, shows that there is good agreement between the simulated and measured results. Although there is generally a good match in the $L C$ equivalent circuit response with the

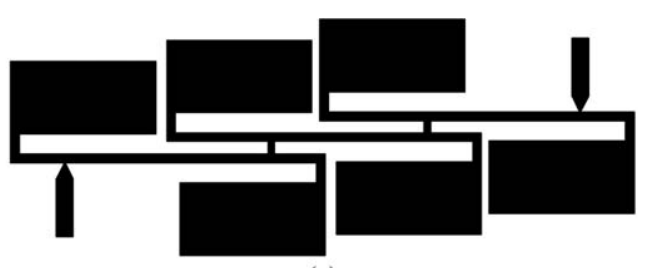

(a)

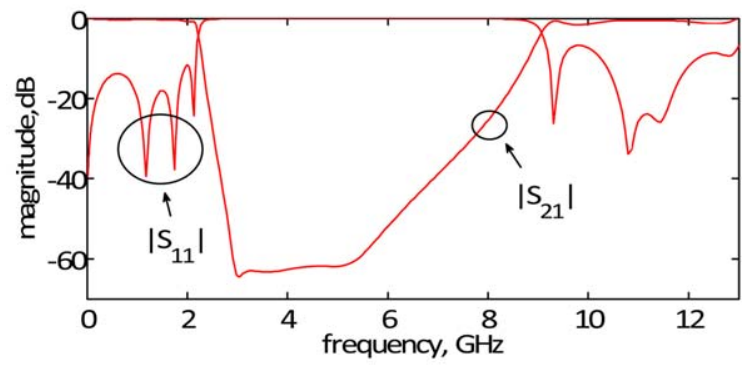

(b)

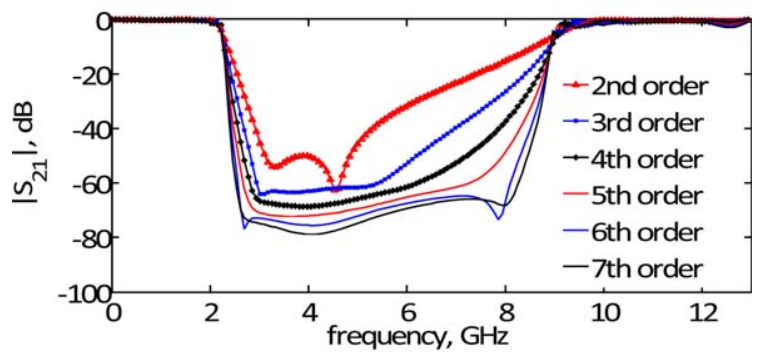

(c)

Figure 4 Layout of the proposed BSF and the simulated scattering parameters frequency responses. (a) Layout of third-order BSF, (b) simulated $S_{21}$ and $S_{11}$ response of third-order BSF, and (c) $S_{21}$ for different orders of BSF. 


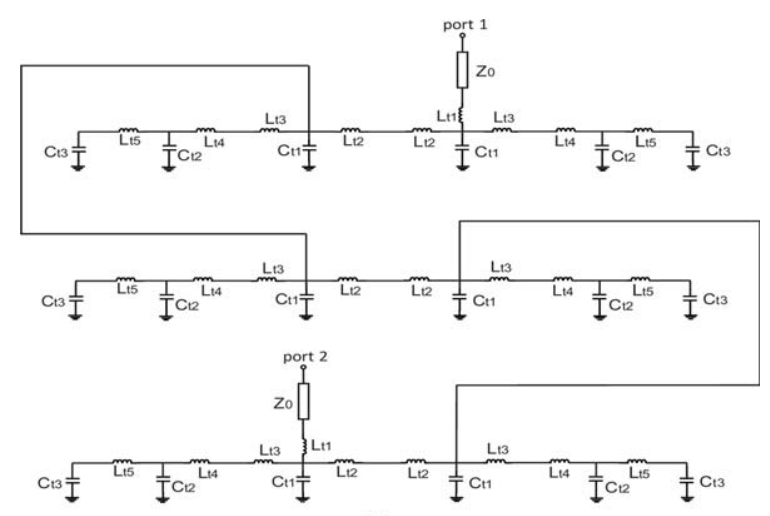

(a)

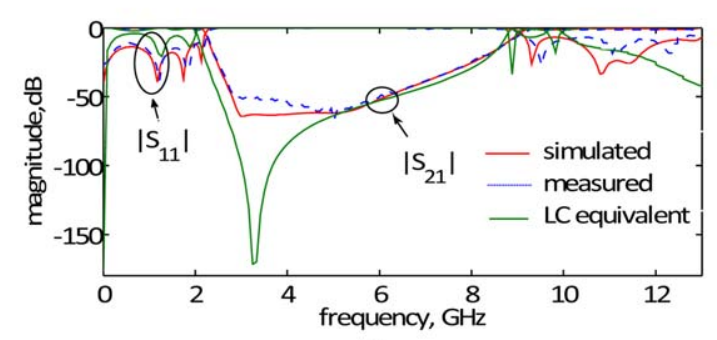

(b)

Figure 5 The third-order BSF, (a) $L C$ equivalent circuit of the third-order BSF, (b) simulated and measured $S_{21}$ and $S_{11}$ scattering parameters of the third-order $\mathrm{BSF}$ and its $L C$ equivalent circuit.

simulated and measured responses, however, the $L C$ equivalent circuit exhibits a slightly lower cut-off frequency and higher rejection across approximately 3$5 \mathrm{GHz}$. This is attributed to the simplified $L C$ equivalent circuit model that does not take into account the microstrip sections interconnecting the resonators, parasitic coupling between adjacent resonators, discontinuity capacitance, open-end fringing fields, and dielectric and conductor loss.

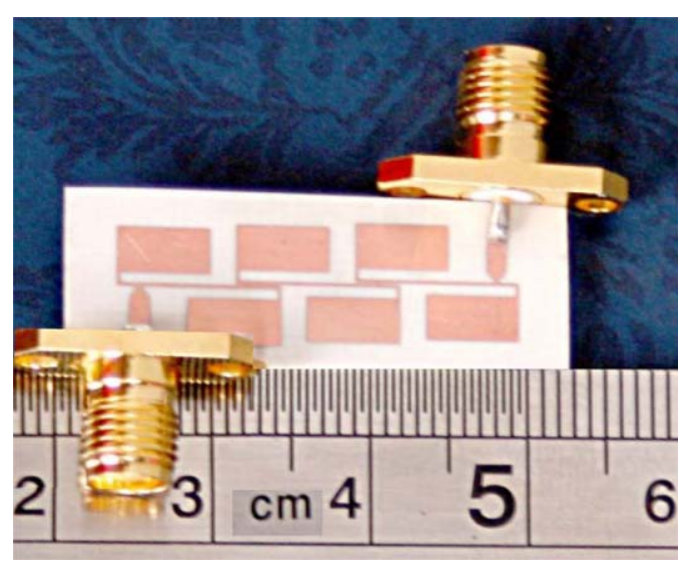

Figure 6 Photograph of fabricated BSF.
TABLE I

\begin{tabular}{lcc}
\hline Reference & $\begin{array}{c}\text { Filter dimensions } \\
\left(\mathrm{mm}^{2}\right)\end{array}$ & $\begin{array}{c}\text { Stop-bandwidth } \\
(\mathrm{GHz}) / \text { Rejection }(\mathrm{dB})\end{array}$ \\
\hline$[1]$ & $10 \times 15$ & $2.92 / \geq 30$ \\
{$[2]$} & $51 \times 89$ & $2.35 / \geq 30$ \\
{$[3]$} & $30 \times 45$ & $0.53 / \geq 30$ \\
{$[4]$} & $25.4 \times 25.5$ & $0.28 / \geq 30$ \\
{$[5]$} & $33.5 \times 32.4$ & $0.09 / \geq 30$ \\
This work & $25.9 \times 8.19$ & $5.12 / \geq 30$ \\
& & $3.49 / \geq 50$ \\
\hline
\end{tabular}

\section{SIMULATED AND EXPERIMENTAL RESULTS}

A third-order BSF was designed and fabricated on Rogers RO4003C substrate with thickness $=0.508 \mathrm{~mm}$, permittivity $=3.38$, and loss tangent $=0.0027$. Figure $5 \mathrm{~b}$ shows excellent correlation between the simulated and measured results. The filter has a $3 \mathrm{~dB}$ bandwidth of $6.91 \mathrm{GHz}$ from 2.2 to $9.11 \mathrm{GHz}$, and its insertion-loss is less than $1 \mathrm{~dB}$ between $\mathrm{DC}$ to $2 \mathrm{GHz}$, and less than 1.3 $\mathrm{dB}$ between 9.2 and $13 \mathrm{GHz}$ corresponding to the lower and upper passbands, respectively. The filter's return-loss is less than $0.5 \mathrm{~dB}$ while the insertion-loss is greater than $50 \mathrm{~dB}$ in the stop-band between 2.70 and $6.19 \mathrm{GHz}$. The photograph of filter is shown in Figure 6. The fabricated filter excluding I/O feed-lines occupies an area of $25.9 \times$ $8.19 \mathrm{~mm}^{2}$. The comparison in Table I shows the proposed technique provides a compact design than [2-5], and has the largest stop-band than [1-5].

\section{CONCLUSION}

The design of a compact BSF with a wide stop-band performance was implemented by interconnecting SIRs. The parameters that controlled the transmission zeros and cutoff frequency of the filter were determined its microstrip structure. A third-order filter was designed and fabricated to verify its performance. Measured results confirm the filter exhibits a wideband response with steep $3 \mathrm{~dB}$ rolloff and high rejection level over a wide stop-band. The filter's planer structure offers enhanced immunity to crosstalk and ground-plane interference compared to DGS BSF configurations.

\section{REFERENCES}

1. R. Habibi, Ch. Ghobadi, J. Nourinia, M. Ojaroudi, and N. Ojaroudi, Very compact broad band-stop filter using periodic L-shaped stubs based on self-complementary structure for Xband application, Electron Lett 48 (2012), 1483-1484.

2. V. Oznazi and V.B. Ertruk, A comparative investigation of SRR- and CSRR-based band reject filters: Simulations, experiments, and discussions, Microwave Opt Technol Lett 50 (2008), 519-523.

3. M. Naghshvarian-Jahromi and M. Tayarani, Defected ground structure band-stop filter by semicomplementary split ring resonators, IET Microwave Antennas Propag 5 (2011), 13861391.

4. M.K. Mandal and P. Mondal, Design of sharp-rejection, compact, wideband bandstop filters, IET Microwave Antennas Propag 2 (2008), 389-393. 
5. Y. Peng and W.-X. Zhang, Compact sub-wavelength microstrip band-reject filter based on inter-digital loaded loop resonators, Microwave Opt Technol Lett 52 (2010), 166-169.
6. J.S. Hong and M.J. Lancaster, Microstrip Filter for RF/Microwave Applications, Wiley, New York, 2001.

\section{BIOGRAPHIES}

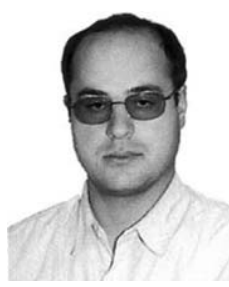

Hamid Asadbeigi received B.Sc. degree in Electrical Engineering in 2002 from the Shiraz University, Shiraz, Iran, and M.S. in Electrical Engineering in 2011 from the Razi University, Kermanshah, Iran. His research interests include microwave and optical circuit design and modeling.

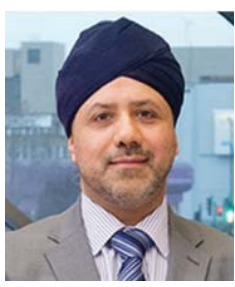

Bal Virdee is Professor of Microwave Communications Technology at London Metropolitan University where he is the Director of Centre for Communications Technology. Previously, he was an R\&D Engineer at Philips, Future Product Design Engineer in the area of RF/microwave communications systems at Teledyne Defence, and has taught at various UK Universities. 